RESENHAS

\section{ORGANISATION SOCIALE, PRATI- QUES SEXUELLES ET RELIGION: LE CAS DES TROIS RELIGIONS MONOTHÉISTES}

Maria José Werebe

Paris : L'Harmattan, 2007, 262p.

Maria José Werebe foi professora livredocente do curso de Pedagogia da Universidade de São Paulo e pesquisadora do Centre National de la Recherche Scientifique - CNRS -, na França. Especialista em educação sexual, situa o comportamento sexual humano para além de condicionantes de ordem biológica. Para a autora, um amplo conjunto de elementos intervém na sexualidade humana, cujas possibilidades de expressão encontram-se na confluência de fatores biológicos e socioculturais. A sexualidade se constitui também em um saber, aprendido e transmitido: "saber como fazer e como não fazer", conhecer o preço do prazer, as condições de negociação do desejo, as regras sociais quanto às trocas e relacionamentos sexuais.

As religiões constituem um importante elemento na conformação e compreensão da sexualidade. Em primeiro lugar porque as práticas sexuais se inscrevem em um contexto cultural e "a religião representa um fator importante no estabelecimento de normas e preceitos que visam reger o comportamento humano". A despeito do avanço da secularização, da separação entre poder religioso e poder laico, e da evolução das normas morais, "as religiões continuaram a exercer uma influência significativa em quase todas as sociedades". Em segundo lugar porque a sexualidade está fundada em um saber e o homem faz intervir o sagrado no dis- curso dele sobre ele mesmo, com o fim de legitimá-lo. Assim, a religião pode se constituir esse instrumento de sacralização de normas, mesmo quando as normas são provenientes de fontes externas independentes de prescrições religiosas, como certas tradições culturais ou leis "estabelecidas pelas autoridades no poder, em função de interesses políticos e econômicos".

A Werebe se propõe a analisar as relações entre as três religiões monoteístas - judaísmo, cristianismo e islamismo - e a sexualidade, para o que entende seja necessário situá-las em seu contexto político, econômico e cultural e considerar a sua evolução no espaço e no tempo. Busca compreender as regras por elas enunciadas e "suas implicações na prática sexual, na organização da família e na sociedade de hoje", procedendo ao exame dos textos revelados (a Bíblia - Antigo e Novo Testamento - e Alcorão), dos textos escritos pelas autoridades religiosas e de interpretações dos textos por crentes e não crentes no que concerne à sexualidade.

Na primeira parte do livro examina o judaísmo, sua história, os pontos centrais de sua doutrina e as regras morais e sexuais estabelecidas no texto, procurando levar em conta as diversas correntes e suas normas e atitudes em relação à sexualidade. Destaca que essas normas e atitudes podem variar de acordo com o grau de adesão do crente às tradições religiosas, com a sua classe social e o país em que vive, e conforme se trate de judeu de Israel ou da diáspora. Em relação à sexualidade, comportamento e normas dos judeus sofreram mudanças significativas ao longo da história, em virtude da influência que receberam da cultura das sociedades em que viveram e das diferenças de interpretação dos textos religiosos entre sábios 
e autoridades religiosas. Enquanto os ortodoxos apregoam uma "moralidade estrita e intransigente", a tolerância e a liberdade de atitudes, inclusive no campo da sexualidade, fazem parte do estilo de vida da maioria dos judeus, particularmente daqueles que vivem fora de Israel.

Na segunda parte, ressalvando a impossibilidade de contemplar toda a sua história, transformações e ramificações, mesmo no interior das principais confissões, a autora analisa o cristianismo em seus principais momentos históricos no que concerne às reciprocidades de interesses políticos e influências culturais mútuas entre religião e sociedades nas quais se instala e para as quais se expande, na forma das três principais confissões: católica romana, orientalortodoxa e protestante. Do ponto de vista da moral sexual o cristianismo é "herdeiro dos preceitos hebraicos e greco-romanos" que, contudo, evoluíram e sofreram transformações ao longo do tempo.

O catolicismo romano é a mais importante dentre as confissões cristãs em face do número de adeptos, da sua expansão e presença em inúmeros países, e da influência que sempre exerceu nos domínios "religioso, político e moral". Prescreve uma moralidade sexual estrita em muitos aspectos, com os renovadores opondo-se aos conservadores nesse campo. Para estes, as relações sexuais têm por finalidade única a procriação, de modo que os métodos contraceptivos, o aborto e o homossexualismo são condenados. No entanto os preceitos morais da Igreja Católica não são totalmente seguidos pela maioria dos seus adeptos: "a contracepção e o aborto são aceitos pela maioria dos católicos, assim como a relação sexual fora do casamento".

No que se refere ao cristianismo oriental-ortodoxo, a autora destaca que, embora haja diferenças entre as suas diversas correntes, este se mostra também muito conservador em relação às questões sexuais. É contudo mais liberal do que o catolicismo romano, uma vez que não prioriza um moralismo estrito, mas sim "o ser humano e a comunhão entre as pessoas". A adoção de métodos contraceptivos cabe à consciência individual e se admite o divórcio, assim como o novo casamento em caso de adultério ou esterilidade.

Quanto ao protestantismo, os preceitos morais de cada uma das correntes no seu interior variam significativamente conforme estejam mais ou menos ligados a tendências liberais ou fundamentalistas. Entre os pentecostais as posições de algumas correntes não são muito rígidas, "mesmo se a Assembléia de Deus, dentre outras, preconiza um certo rigor"; na França, os protestantes adotam posições majoritariamente liberais quanto à moralidade, sendo favoráveis ao uso de métodos contraceptivos, tolerantes quanto à relação sexual pré-conjugal e mesmo quanto ao homossexualismo, e admitem o aborto em alguns casos; contudo, ainda na França, as correntes denominadas evangélicas não chegam a ser tão liberais. No entanto, "os conservadores americanos de direita pregam uma moral extremamente retrógrada, contra o aborto e os homossexuais", chegando até, em alguns casos, a propor a proibição de salas de aula mistas nas universidades.

Na terceira parte do livro, a autora trata do islamismo, a "mais jovem" das religiões estudadas, de sua evolução e expansão desde que foi criado, suas correntes e as normas e regras morais e sexuais que thes correspondem, fazendo também uma rápida abordagem do feminismo árabe-muçulmano, assim como da situação das mulheres em alguns países muçulmanos. Chama a atenção para a "grande diversidade étnica e cultural do mundo muçulmano" (islã negro, árabe, iraniano etc.) e para a tendência de considerar certas regras associadas ao Islã "como sendo universais", quando na verdade essas são interpretadas de modo diferente de 
acordo com o país, categorias sociais, e comunidades imigradas. Nos países em que o islamismo é a religião principal ou oficial, obviamente a tendência é que as regras sejam mais estritas, embora algumas delas sejam mais "determinadas por tradições culturais do que pela religião". Mesmo nesses países é possível verificar progressos em direção à maior liberalidade quanto à moral sexual e aos direitos das mulheres. Exemplos nesse sentido são a Turquia (estado laico) e a Tunísia, onde o aborto e a adoção de métodos contraceptivos são admitidos, e a poligamia e o repúdio de mulheres é proibido (o divórcio é permitido na Turquia).

Nas comunidades imigradas, alguns grupos integristas - minoritários - "tentam impor regras morais rígidas, às vezes por meio de métodos violentos", mas a maioria dos imigrantes muçulmanos se integra à cultura local, adotando um islamismo "moderado, compatível com as liberdades democráticas". De modo geral apenas os grupos "radicais" são favoráveis a uma moral sexual rígida. Contudo, de acordo com a autora, ao contrário do que ocorre com os cristãos e judeus, não se constata queda da prática religiosa entre os muçulmanos, principalmente nos países em que eles são majoritários.

Para além da riqueza de dados e informações, um dos méritos desta obra está no próprio fato de voltar o olhar para as relações entre religião, sociedade e sexualidade. A análise transversal não dá margem a que se corra o risco de limitar e/ou excluir da problemática de gênero parcela considerável de mulheres, uma vez que o fator religioso incide sobre as relações sociais de sexo tanto de forma indireta, pelos imbricamentos existentes entre cultura, saberes e poderes laicos e religiosos, quanto de forma direta, em face da forte presença de muIheres nas religiões.

Outro elemento de destaque está na abordagem do fenômeno religioso como pro- cesso mais dinâmico e amplo do que as representações acerca das religiões ou de suas manifestações dominantes poderiam fazer crer. A autora evita uma abordagem simplista' mas comum, mesmo nos meios acadêmicos, que tende seja a afirmar uma "missão redentora" da ciência, da república laica, de todas as instâncias que representariam, enfim, a libertação da religião, da falsa consciência de si para a "real" racionalidade e liberdade, seja a exaltar um pretenso papel "libertário" da religião. Como se as religiões tivessem sempre e apenas uma face - ou libertadora ou de reforço do patriarcado - e jamais as mulheres, dentro de uma visão religiosa, pudessem aceder ou se beneficiar da condição de sujeito em contraposição à sociedade laica, que sempre Ihes favoreceria esse acesso.

$\mathrm{Na}$ perspectiva da autora, a realidade ou as realidades dessa relação entre religião, sujeito e sociedade é bem mais complexa. $\bigcirc$ processo de crescente autonomização dos sujeitos se consolida também no (e talvez mesmo a partir do) campo religioso, possibilitando aos "crentes modernos" comporem as suas crenças e exercerem a sua fé, sem necessariamente "respeitar todas as regras impostas pela sua religião" ou pelas autoridades religiosas. De fato os dados indicam que "o retorno do sentimento religioso não impediu uma queda [na observação] das práticas religiosas, em particular entre os cristãos e os judeus". Se, no entanto, há um retorno do sentimento religioso, ele é explicável em parte pelas desigualdades e injustiças sociais, pelo confronto de etnias e dificuldades de aceitação da alteridade. Cenário no qual reivindicações étnicas, políticas ou identitárias, estão ou são, em muitos casos, associadas a um

I. WOODHEAD, L. Mulheres e gênero: uma estrutura teórica. Revista Eletrônica Rever, v.2, n. I . Disponível em: www.pucsp.br/rever. 
pertencimento religioso, ao mesmo tempo em que se verifica crescimento de integrismos e fundamentalismos, que tanto se podem configurar em "solução de desespero" quanto em afirmação ou desejo de poder.

Com essa perspectiva sensível e lúcida a autora conclui que o problema não está na religião em si, mas no que se faz dela, ou com ela. Não se trata, no caso, de 'resgatar' as religiões ou de justificá-las, mas de reconhecer a complexidade de fatores envolvidos na adesão e nas formas de manifestação religiosa, tanto do ponto de vista dos sujeitos religiosos, quanto no que se refere às relações entre religião e sociedade e das implicações destas sobre as relações de gênero no âmbito interno e externo ao contexto religioso.

Naira Carla Di Giuseppe Pinheiro dos Santos Núcleo de pesquisa em gênero e religião Mandrágora/NETMAL Doutoranda em Ciências da Religião pela Universidade Metodista de São Paulo nairapinheiro@gmail.com 